\title{
Teaching Engineering Graduate Online Students in the U.S. from Pakistan-A Case Study
}

\author{
Adeel Khalid ${ }^{1}$ \\ ${ }^{1}$ School of Engineering, Southern Polytechnic State University, Marietta, Georgia, USA \\ Correspondence: Adeel Khalid, School of Engineering, Southern Polytechnic State University, 1100 South \\ Marietta Parkway, SE, Marietta, GA. 30060, USA. Tel: 1-678-915-7241. E-mail: akhalid2@spsu.edu
}

Received: May 8, 2012 Accepted: May 21, 2012 Online Published: July 18, 2012

doi:10.5539/hes.v2n3p9 URL: http://dx.doi.org/10.5539/hes.v2n3p9

\begin{abstract}
Outsourcing is seen from various points of views by individuals in different industries. When it comes to educating science and technology students, and for that matter, students of any discipline, up until recently, outsourcing was not a possibility. With the recent advances in computer and network technology, it is now possible to teach a live online distance-learning course from anywhere around the world. The need for the instructor and the students to be physically present in a common classroom is eliminated. In an on-line course, students and teacher get the opportunity to interact with each other. The computer-based distance learning approach is still in its relative infancy. But since the teaching and learning is done online, via the use of computers connected to inter-connected networks and satellites, the need to be geographically co-located does not exist any longer. The instructor and the students can be physically distributed at various locations, around the city, around the country, or around the world and still be able to teach and learn from each other as if they were present together in the same classroom. Since the medium of instruction is computers, the instructors and students can be outsourced. The flip side of the argument is that since the instructor is not physically present in the same room with the students, they do not get to interact with each other face to face. The instructor can continue to derive a complex mathematical equation without realizing that a student has walked away from their computer. This paper explores the positives and negatives of distance learning distributed education. Advantages and disadvantages of DL are discussed and a few solutions to the challenges, experienced by the instructors, are addressed.

The research is based on the author's experience of teaching online courses from within the city, across the states, and finally across the continents. Amongst other findings, the author discovered that when teaching an online distance learning class, distance is not a factor. While teaching online classes, the author travelled across different cities, states, and internationally and the students did not realize that the instructor was out of town and could not meet with them in the office after class.
\end{abstract}

Keywords: distance learning, online education, travel teaching

\section{Motivation and Background}

The author had the opportunity to travel extensively while teaching. The travels included those within a large metropolitan city, across states, across countries, and across continents. The goal of an online instructor is to continue the class instruction and to stay on the semester long schedule, while traveling. Traveling could be for a variety of reasons including conferences, professional development, workshops, grants, seminars, short courses, and other academic and non-academic activities. With the global internet connectivity, continuation of online courses is feasible during these extensive travels. The new technology of the Web offers unique prospects for promoting a reflective and collaborative learning environment (Bates, 1996).

In electronic text based communities of learners, our geographically and socially isolated students have the opportunity to establish communicative relationships with each other and to reflectively co-construct their knowledge by engaging in open and critical discourse (Maor, 1999).

Jegede recounts that the "distance learner, who is usually an adult in some form of employment, is characterized, amongst other qualities, by autonomy, persistence, independence, self-direction and flexibility" (Holmberg, 1995), while Schrum and Luetkehans (Schrum, 1997) specify that "the great majority of adults learning at a 
distance were reported to be in the 20-40 age range and studying on a part-time basis from their homes while maintaining full-time jobs".

Furthermore, Wedemeyer and Childs (Wedemeyer, 1961) assign self-motivation, organizational skills, and the ability to concentrate well as ideal qualities a distance student should possess, while the educational program itself should maintain clear goals and objectives, manageably sized lessons, and rapid feedback from the instructor in order to coincide with the qualities of the students.

Additional requisite qualities include a comfort level with the delay in engagement and with the loss of control (Raths, 1999). Sherry and Wilson (Sherry, 1997) see a relationship between the loss of instructor's control with a corresponding awakening within students; students come to the "realization that the instructor is not the sole authority or repository of answers, and that the answers to real problems aren't as simple as they might seem!"

Both students and instructors in a Web-based environment must possess certain characteristics. Student qualities include maturity, self-discipline, organizational and management skills, commitment, and assertiveness. Underlying these, qualities such as the ability to articulate oneself through a textual means, and the ability to thrive in a group learning environment by participating fully assume importance (Buchanan, 1999).

The author got a chance to travel across the continents and stay in Pakistan while teaching full semester load of online distance learning course at Southern Polytechnic State University (SPSU). The courses were taught using WebCT and online live interactive module known as Horizon Wimba. The classes were conducted from Lahore University of Management Sciences (LUMS) School of Science and Engineering. One of the concerns that the author had was the bandwidth available in Pakistan to conduct a synchronous class. The class material is shared with students and the instructor and students correspond synchronously. The LUMS campus was chosen because of the uninterrupted broad band Internet access. The power outage, which is prevalent in most developing countries, was not an issue on LUMS campus because the campus has its own power generation system. The other issue was the difference of time zones. The author had to start the day at 2am PST (Pakistan Standard Time) to start a class, which would translate to 6pm EST (Eastern Standard Time.) That took a little getting used to for the instructor. The students did not even realize that the instructor was not on campus at SPSU. The good thing about the online live class management system is that it can handle 20 or more students logged in simultaneously from different parts of the world. For the purpose of the classes that the author taught remotely, there did seem to be a limit on the number of students who could log in to attend the live class. At certain times there were a few interference issues encountered over the internet but none of them were significant enough to affect any of the class sessions. There were some in-frequent delays but they were minor and students did not seem to be bothered because of them. The author was able to teach three graduate level online classes successfully from approximately 8000 miles away from campus. Figure 1 shows a snapshot of the synchronous online class environment using Horizon Wimba. Students had the option of asking questions either using their microphones or by typing their questions in the chat window. The instructor encouraged student class participation.

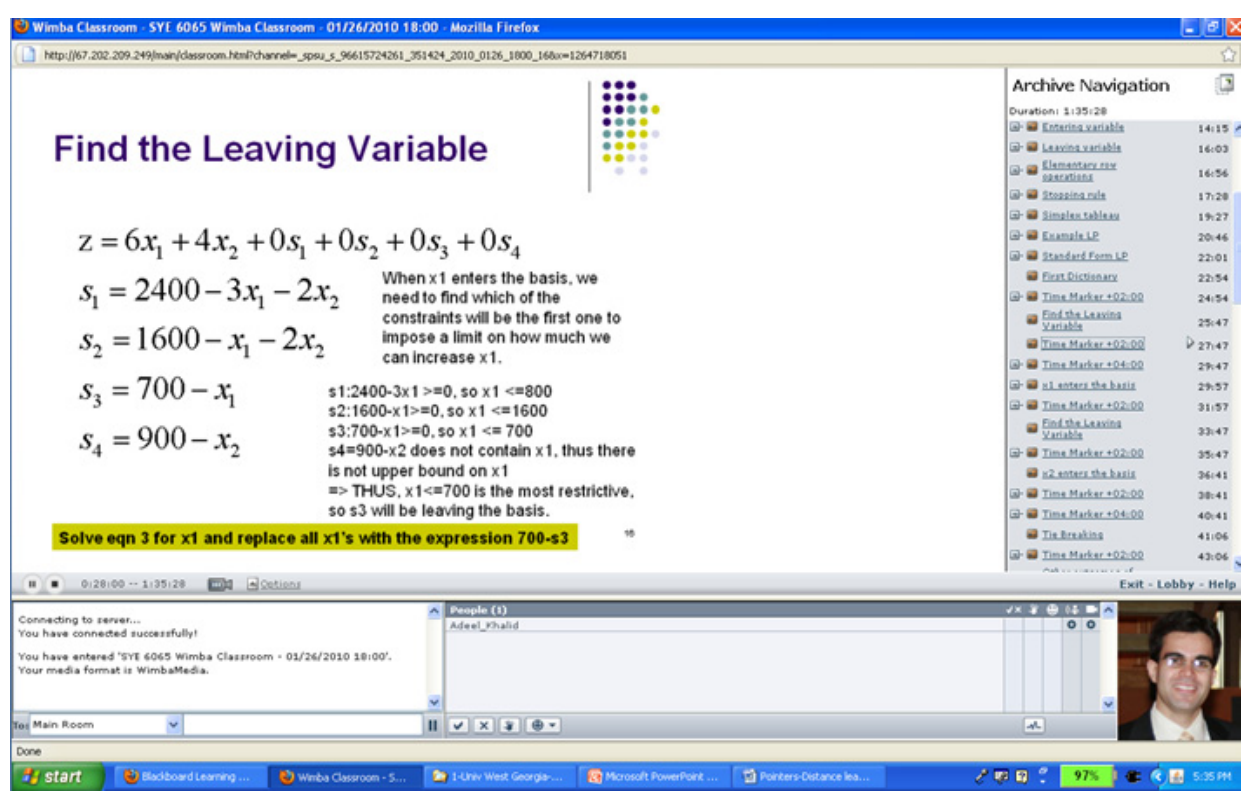

Figure 1. Snapshot of the synchronous online class environment using Horizon Wimba 
While at LUMS, the author also taught an on-campus 'Operations Optimization' course to the local students. In the author's experience, one of the best ways to learn is by experiencing or doing it. The author encourages students to actively participate and present material in class. The student learning increases significantly if they have to research material and present it in class in front of their peers.

Confucius once said:

"If all I do is hear, I will forget. If I hear and see, I will remember. If I hear, see and do, I will understand"

The online environment allows for active student participation. Edgar Dale (Dale, 1946) in 1946 introduced the cone of learning in his textbook on audio-visual methods in teaching. The organizing principle of the cone was a progression from most concrete experiences (at the bottom of the cone) to the most abstract (at the top.) The original labels for Dale's ten categories are: Direct, Purposeful Experiences; Contrived Experiences; Dramatic Participation; Demonstrations; Field Trips; Motion Pictures; Radio - Recordings - Still Pictures; Visual Symbols; and Verbal Symbols. Learning by doing is generally longer lasting than learning by seeing. The author believes that one of the best teaching methodologies is to get the students involved in the process - often known as student centered learning. The on-line environment provides a unique challenge for student centered learning. The graduate students are generally mature and perform well in online environment. They also realize the advantages of online classes that out-weigh the difficulties in such an environment.

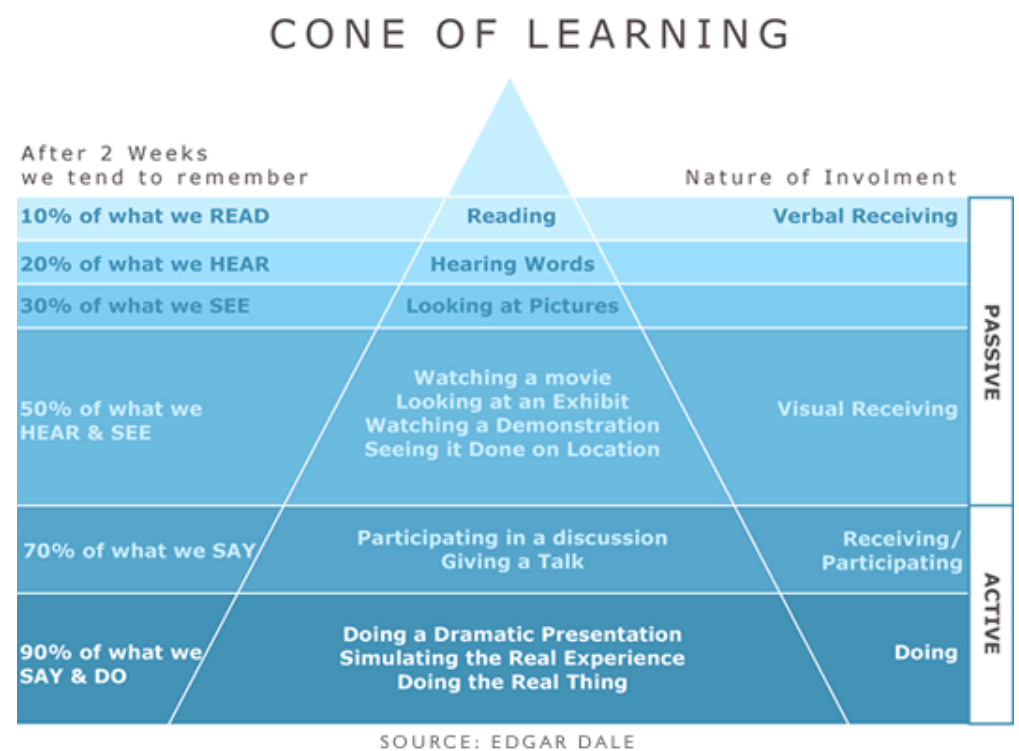

Figure 2. Cone of Learning (Buchanan 1999)

\section{Faculty Surveys}

A faculty survey was conducted to collect instructor's impression of the plusses and minuses of on-line teaching and learning. The survey included faculty from SPSU, LUMS and Georgia Institute of Technology campuses. The simple survey asked for positives and downsides of teaching online and any other appropriate feedback. The positives and negatives listed in this paper are not intended to be all-inclusive. The list of positives and negatives are a collection of points that the author deemed most appropriate for synchronous graduate level classes.

\section{Upsides of Online Teaching}

Several researchers have identified a number of positives of online teaching. Buchanan points out that through the content, in the various forms of text, images, video, or other multimedia platforms, reflection and engagement take place on a scale much different than traditional environments. Buchanan further asserts that the asynchronous nature of the course enables class members the time to examine an issue before responding, but the omnipresent availability of the course permitted and fostered a sense of immediacy and presence. This duality is unsustainable elsewhere, and lends to a pedagogical model that offers "the best of both worlds:" Time and engagement with the learning process and with the content, as well as the ability and availability to participate in this process at any time. Because the learning environment is unlimited in time and space, perspectives are not disregarded. The constraints of the classroom often forbid us from hearing from everyone. 
With the openness of the Web forum, multiplicitous voices emerge. The "lattice" of the Web classroom is comforting and encouraging.

With peers and their expertise at each other's omnipresent disposal, the formation of a learning community grounded in professional discourse appears to grow naturally. Students, "attending" class each day, come to know each other more thoroughly than their weekly counterparts.

The author experienced that the online environment provides the opportunity to the working professionals and mature students to bring their knowledge back to the classroom. The instructor can leverage that knowledge to add value to the class. In a typical undergraduate classroom, it is unlikely to get students with real world experiences. Often times, the graduate students are the top $15 \%$ of their undergraduate class. They are mature and bring value to the class. It is the responsibility of the instructor to exploit that knowledge so everyone can seek benefit from it.

The online environment also provides schedule flexibility. Flexibility of schedule is of significant importance to graduate students and working professionals. A student can take the online class while traveling on business, visiting a relative or when on vacation. The environment also provides the same flexibility to the instructor. The instructor can teach from their residence, and they can continue to teach during epidemic or natural disaster. During the fall 2009 semester, when the author taught the online class from Pakistan, there was a major flood that caused the SPSU campus to shut down. Since the classes were being taught on-line, the students were not required to go to campus to attend the class. The campus network system continued to operate. The instructor was able to conduct live classes. Those classes would typically be cancelled in ordinary circumstances. Since a number of students were affected due to flooding, they were not able to attend the live classes. Horizon Wimba allows the classes to be archived. The students were able to listen to the archived lectures at their convenience at a later point. The lecture archive is a big advantage of online classes. It does not only help students to catch up with missed classes, but it also provides a useful platform for them to go back and review the course at their convenience. The archives are available anywhere, anytime. The archives can also be saved in portable media format. Students can download the lectures and listen to them on their personal phones or other audio devices. The entire online course is modularized. So a student does not have to sit through the entire lecture to understand one concept. They have the controls to play and stop the lecture at their discretion. This helps them review and focus on the point that they did not understand in the class without having to review the entire lecture. This flexibility is not necessarily available by default in an on-campus classroom environment.

The instructors surveyed also thought that although it is hard to develop an online course, but once developed, it is highly reusable. A number of modules in an online course can be re-used. This includes the reuse of archived lectures. The voice-over lectures are helpful for qualitative and quantitative material.

One of the greatest advantages of online classroom is the ability to simultaneously teach large number of students all over the world. Students do not have to commute or travel to go to school. They could seek admission in the universities of their choice around the world and take classes without having to step out of their home. This helps reach out to students in remote area who might otherwise not be able to get quality education and in some cases any education at all. This helps reduce the cost of education. Students do not have to pay to live on or near campus. The commute cost is eliminated. The same flexibility is available to instructors. An instructor can be in any part of the world where they have access to the online class material, and they can conduct the class without worrying about going to campus.

The Wimba classroom provides a platform where students can talk to each other in breakout rooms. This simulates the hallways outside the classrooms where students can discuss homework, projects or other type of collaborations that they need to discuss outside the classroom. They can also meet online outside the class times. This collaboration is ideal for combined projects, research and development.

The online class is also green. It requires fewer or no papers. The white or blackboard is not used. In long run, that also helps reduce the cost of education.

The above is not an all-inclusive list of positives of on-line teaching. These points are a summary of a few observations that the author had during the course of distance online teaching. Some of these points were collected from the earlier mentioned survey results from the online instructors from various universities.

\section{Downsides of Online Teaching}

While there are lots of advantages of online teaching, there are still some drawbacks or limitations that need to be considered. The following list of cons of online teaching is not intended to be an all-inclusive list. It is a list of few points that the author observed. There are also a few points that were gathered from the faculty survey. 
Any faculty member teaching online needs to understand that not all courses can be taught online with the same level of effectiveness. Some courses are better suited for online environment than others. Even with the latest advances in technology, there are still certain courses that are more effective when taught in an on-campus environment. Lab courses like biology, chemistry, and physics, where students need to interact with apparatus e.g. flasks, chemicals, Bunsen burner etc. are not feasible online. Similarly engineering labs where students get involved in hands-on activities are not feasible in online environment.

One of the biggest frustrations that the author feels in an online classroom environment is the lack of face-to-face interaction between the instructor and students. When an instructor teaches an on-campus course, they can get a direct and immediate feedback from students by looking into their eyes. That immediate feedback is not available in an online environment. There are ways to improve the student-teacher and student-student interaction but the interaction is not close to what one can expect when all participants are physically present in the same room. Due to the lack or absence of this interaction, team-work is hard to accomplish. Since students do not get a chance to meet with each other in person, they are more reluctant to interact with each other and work in groups. Students often do not want to interact with groups. They are also hesitant to discuss the course material or assignments online with each other. This hinders the student's ability to present their work in groups. In the author's experience, most students prefer on-campus classroom environment for presentations - despite knowing that everyone can see them. When asked to present online, they are often either reluctant or do not perform as well as they would otherwise. This may have to do with the 'fear of unknown.' This also makes the environment more formal than an on-campus class.

From an instructor's perspective, there is a lot of intensive preparation required. Preparing for an online course may take significant amount of time and effort from the instructor compared to an on-campus class. Delivering an online lecture also presents a set of challenges. The instructor cannot write on the board or walk around in the room. The instructor is usually stuck in the chair looking at a computer screen. That decreases the dynamism that some instructors enjoy in a classroom environment.

There is also a lot of administrative work required from the instructor in an online class. This includes uploading, and downloading lectures, archiving lectures, keyboard activities, and other secretarial work. This requires extra effort and time from the instructor and sometimes may even distract the instructor from the objectives of the course.

Grading homework and assignments also poses certain challenges. The instructor cannot mark on the student's work unless if they are using a touch sensitive screen. The other alternative is to print the student work, mark it, and then scan it back for student review. This also causes lots of extra work and time commitment from the instructor. The re-grading may take even more work and may be very difficult to do. The alternative is to design the homework and quizzes in such a manner that they do not require marking e.g. multiple choice questions, short answer questions, true false questions etc. But some of these techniques may not be applicable depending on the type of course being taught.

One of the arguments gathered from the faculty survey was related to the industry perception of online degrees. The goal of students going to school on campus is not only to impart knowledge but also the character and personality building. The instructor argues that the personality buildup process is missing in an online classroom environment. Students do not get a chance to meet with other students, faculty, and colleagues in person. The inter-personal and communication skills may not develop or may not be at par in an online environment when compared to traditional on-campus classes. The general perception of the online programs in the industry is still not as favorable as the traditional on-campus programs. This may have to do with the fact that there are still not very many online programs available. With the advances in technology, it is expected that in a few decades, if not a few years, the online distance learning will become a norm. The negative stigma attached with the online degrees will hopefully go away because of that. The graduate level online classes are relatively more acceptable in the industry.

Engineers are process / algorithm based learners. They do not learn well with bullet-points in a slideshow. A typical engineering class will show the process or evolution of a theory or a mathematical concept. This becomes second nature to engineering students after years of learning and practice. They do not need to see words or final equations, but instead the evolution of those equations. Unfortunately Power-Point takes that away. When engineering students are shown bullet-points, it becomes rather difficult to grasp the concept. The online environment sometimes forces the instructor to show the final result or final equation, as opposed to deriving the equation or showing the flow, or process of evolution. This makes the online teaching and learning even more challenging. Sometimes, publishers jack-up prices and instructors are bought into it because they sell the entire 
course material together including the online material as a package. With the advent in technology, instructors will be able to write on the board, just like in an on-campus class, and the notes will be digitized. Students will be able to follow the evolution / flow of engineering concepts. Students need to see the charts, flow charts, and figures.

In an online environment, communication is intense. Since there is little or no immediate feedback for the instructor, concepts may not be clear to the students and the instructor's pace may end up being faster than what students expect. Students may miss important concepts and announcements because of that. This requires more facilitation and administration from the instructors - instructors may need to be trained for this process. This may also cause an otherwise very good instructor to be inefficient or ineffective in an online class.

Another challenge in an online class is proctoring exams for undergraduate and graduate students. Students may be tempted to cheat due to the absence of a proctor. Often times, students are asked to take the exam in front of an external proctor. The proctor has to be paid for their time, which causes additional over-head.

Long-term online teaching can cause health issues including back pain and eye problems. This may be true for older faculty. As discussed earlier, the advent in technology, may allow the faculty to move around the room, write on the board and not have to stare at a computer screen for extended periods of time. This may help alleviate the long-term health issues.

The biggest concern that the author has with online teaching and learning is the lack of first hand feedback from students. If the instructor does not get that feedback, it is very difficult to improve the online teaching. Any system that does not continuously strive to improve itself will get left behind and will eventually perish.

\section{Other Feedback}

In addition to the above pros and cons of online distance teaching, there were a few comments received from the faculty survey that are worth addressing.

Online teaching is becoming more and more common. Georgia Institute of Technology offers several online courses including a Masters degree in Aerospace Engineering. Aerospace Engineering is often considered a very difficulty degree to obtain. Georgia Tech is one of the leading universities in Aerospace Engineering. When graduates from this program go in the industry, it will gradually change the industry's perspective towards online degree programs. Southern Polytechnic State University offers online Masters in Systems Engineering. Like Georgia Tech and SPSU, there are several other top universities across the U.S. and around the world that are beginning online degree programs. With this new thrust, the technology to support online programs will be developed and the cons discussed will be eliminated.

As an instructor, one can adopt one's teaching style to online teaching. It may take a little getting used to. There is a slight learning curve for online teaching, even for seasoned instructors. But there are some instructors who have devised techniques applicable for effective online teaching. These instructors do exceptionally well and get good student feedback.

Several survey respondents indicated that online classes are better suited for graduate students. Graduate students have higher level of maturity. The cheating concerns are reduced. Students are more responsible and serious towards their education. Typically only the top $15 \%$ of an undergraduate class goes to seek a graduate degree.

\section{Recommendations}

There are ways to improve online teaching and learning. Online classes are not suitable for all levels of students. A technically savvy student is more likely to do well online, than a novice. Students can do a self-evaluation to see whether they are ready for an online class. Buchanan recommends that to avoid failure and inefficacious pedagogy in online Web-based environments, potential students should respond formally to a set of criteria. This criterion may include a survey instrument developed by each institution and distributed before admission to a Web-based program or course; this survey may include such questions as:

1. Are you able to work independently?

2. Will you sacrifice personal time to complete assignments and readings?

3. Can you write clearly and articulate your thoughts coherently?

4. Are you a self-starter?

5. Are you able to manage time?

6. Do you have strong study skills? 
7. Do you need direct lecture to understand materials?

8. Are you comfortable asserting yourself in a group?

9. Will you divulge personal information and be comfortable hearing others' information?

10. Are you computer literate?

Similarly some instructors do better in online teaching than others. Instructors need to be trained for effective online teaching. Furthermore, Buchanan asserts that instructors should complete a self-assessment survey before teaching in the Web environment. They absolutely must not learn how to teach online as they proceed, but they should be trained and confident before they enter the online classroom. The instructor's role in a Web-based environment demands newfound skills and pedagogical philosophies.

\section{Conclusions}

In this paper, the author reviews the positives and the negatives of online teaching and learning. Several online instructors were surveyed and their feedback was analyzed. The online teaching offers plethora of advantages including the schedule flexibility, re-usability of course material, reduced cost of education, use of latest technology, ability to archive lectures, ability to tap on resources from around the world, ability to travel and still be able to attend the classes from any part of the world etc. On the flip side, there are several disadvantages or shortcomings of online teaching. These include the lack of face-to-face interaction, lack of teamwork, intensive preparation required from the instructor, poor industry perception of online degrees, inability to teach lab courses online, difficulty associated with proctoring online exams, little or no feedback received from the students etc. The online education is still far from perfect. With the rapid advances in technology, it can be expected that in a few years, all the cons of online education can be eliminated. Until then, the instructor and the student need to do a self-evaluation to determine whether online education is right for them.

\section{Acknowledgements}

The author would like to acknowledge Drs. Renee Butler, Walt Thomas, and Ken Jackson of Southern Polytechnic State University for their advice and help, Daniel Schrage of Georgia Tech for his support, Sultan Sial, Mohammad Abubakr for providing a platform for online teaching at LUMS and several other faculty members for filling out the survey.

\section{References}

Bates, D. (1996). Constructivism: Implications for the design and delivery of instruction-Handbook of research for educational communications and technology. New York: Simon \& Schuster Macmillan.

Buchanan, E. (1999). Assessment measures: Pre-Tests for successful distance teaching and learning. Online Journal of distance learning administration.

Dale, E. (1946). Audio-visual methods in teaching. New York: The Dryden Press.

Holmberg, B. (1995). Theory and practice in distance education. New York: Routledge.

Maor, D. (1999). A professional development program to enhance teachers' understanding of the use of a constructivist multimedia learning environment. Learning Environment research: An International Journal.

Raths, D. (1999). Is anyone out there?. Inside Technology Training. 32-34.

Schrum, L. a. (1997). A primer on distance education: Considerations for decision makers. Washington DC: AECT.

Sherry, L. a. (1997). Transformative communication as a stimulas to Web innovations. Englewood Cliffs: Educational Technology Publications.

Wedemeyer, C. a. (1961). New perspectives in university correspondence study. Chicago: Center for the Study of Liberal Education for Adults. 